(1999). Words and prosodic phrasing in Lushootseed narrative. T. A. Hall \& U. Kleinhenz (eds.), Studies on the Phonological Word, 23 - 46. Amsterdam: Benjamins.

\title{
Words and prosodic phrasing in Lushootseed narrative ${ }^{*}$
}

\author{
David Beck \\ University of Toronto
}

\section{Introduction}

As with so many of the basic terms in linguistics, the term "word" is one which is often taken for granted and, although it is characterized differently in different domains of linguistic research, there is often a tacit assumption that the entity as defined at one level of description is the same entity singled out at another level. Thus, in the syntax "word" is often used to mean a "single lexical item" whose linear position and inflectional properties are manipulated by the morphosyntax (Trask 1993), whereas the phonological word is generally defined in terms of the domain of lexical stress assignment or the application of other low-level phonological rules (e.g. Nespor \& Vogel 1986). The assumption that what is a word for the syntax is equivalent to what is a word for the phonology, however, has been called into question by a good deal of recent work, including a number of the papers in this volume, which seem to indicate that the two types of word do not necessarily match. Although there is a good deal of symmetry between the two in the familiar Indo-European languages that have been the focus of the bulk of investigation, the greatest challenge to the idea that the syntactic-word is isomorphic with the phonological-word comes from languages which are, relatively-speaking, morphologically complex (Evans 1986 on Yidiniy; Czaykowska-Higgins 1997 on Nxa?amxcín) or which are classified as polysynthetic (Rice 1993 on Slave; Russell (this volume) on Cree and Lakhota). Work on the latter group in particular seems to suggest that what is a word for the morphosyntax may actually correspond to

\footnotetext{
*Thanks are owed to Jean Balcaen, Trisha Causley, and a number of attentive audiences for listening to more confused earlier incarnations of this paper, to Keren Rice and to Elan Dresher for helpful comments on the current version, and to Elan for convincing me that this stuff was kind of cool. The assistance of David Bennett has also been invaluable in sorting out some of the intricacies of the intonational phrase. While it is hard to believe that with such able help any errors could possibly remain, those that do can be ascribed to me alone. This work has been supported by the Social Sciences and Humanities Research Council of Canada through a Doctoral Fellowship to the author and a SSHRC research grant to Elan Dresher and Keren Rice.
} 
a higher-level phonological unit consisting of more than a single phonological word-perhaps even to the phonological phrase.

In this article I will examine some data from the Salishan language Lushootseed which shows that, in fact, the phonological word differs markedly from what can reasonably be called a word in the morphosyntax even in languages that are only mildly polysynthetic, and that what is called a word in the syntax may not be a word in the phonology. To begin, in section 2, I present the basic patterns of Lushootseed prosody and the constraints that govern phonological phrasing, using an informal definition of the two primary units of the phrasing process, the clitic and the phonological word; following this, in section 3, I discuss the interaction-or, more accurately, the lack thereof - between the processes of phonological phrasing and the syntax of the language. In section 4, I return to the ad hoc notions of clitic and word used earlier and discuss how these might be defined for the purposes of phonological phrasing. I will argue that these units are not amenable to a syntactic definition, but instead depend on a combination of lexical and phonological criteria, the implications of which are discussed in the conclusion to this article.

Lushootseed is a language of the Salishan family spoken in the Puget Sound area of Washington State. It has the consonantal inventory given in (1).

(1) Lushootseed consonantal inventory

\begin{tabular}{|c|c|c|c|c|c|c|c|c|c|c|}
\hline & \multirow[t]{2}{*}{ labial } & \multirow[t]{2}{*}{ alv } & \multirow[t]{2}{*}{ lateral } & \multirow[t]{2}{*}{ al-pal } & \multicolumn{2}{|c|}{ velar } & \multicolumn{2}{|c|}{ uvular } & \multirow[t]{2}{*}{ glottal } \\
\hline & & & & & & unrnd & rnd & unrnd & rnd & \\
\hline stops & $\begin{array}{l}\text { plain } \\
\text { glottalized } \\
\text { voiced }\end{array}$ & $\begin{array}{l}\mathrm{p} \\
\mathrm{p} \\
\mathrm{b}\end{array}$ & $\begin{array}{l}\mathrm{t} \\
\mathrm{t} \\
\mathrm{d}\end{array}$ & & & $\begin{array}{l}\mathrm{k} \\
\mathrm{k} \\
\mathrm{g}\end{array}$ & $\begin{array}{l}\mathbf{k}^{\mathrm{w}} \\
\mathbf{k}^{\mathrm{w}} \\
\mathrm{g}^{\mathrm{w}}\end{array}$ & $\begin{array}{l}\mathrm{q} \\
\mathrm{q} \\
\mathrm{q}\end{array}$ & $\begin{array}{l}q^{w} \\
\dot{q}^{w}\end{array}$ & $?$ \\
\hline affricates & $\begin{array}{l}\text { plain } \\
\text { glottalized } \\
\text { voiced }\end{array}$ & & $\begin{array}{c}\mathrm{c} \\
\dot{c} \\
\mathrm{~d}^{\mathrm{z}}\end{array}$ & $\chi^{7}$ & $\begin{array}{l}\check{c} \\
\check{c} \\
\check{j}\end{array}$ & & & & & \\
\hline fricatives & & & $\mathrm{s}$ & 4 & $\check{s}$ & & $x^{w}$ & $\check{x}$ & $\check{\mathrm{x}}^{\mathrm{W}}$ & $\mathrm{h}$ \\
\hline resonants & $\begin{array}{l}\text { plain } \\
\text { laryngeal }\end{array}$ & & & 1 & $\begin{array}{l}\mathrm{y} \\
\mathrm{y}\end{array}$ & & $\begin{array}{l}\mathrm{w} \\
\mathrm{w}\end{array}$ & & & \\
\hline
\end{tabular}

(based on Hess 1995: 265) 
There are three vowels-/i/, /u/, and /a/-which occasionally show a phonemic long/short distinction, and /ə/, which has only the short variant. Word-level stress is largely predictable and all vowels can be stressed, stress falling on the first non-schwa of the morphological root of a major class lexical item (Bianco 1995) or any other lexeme that can be considered a phonological word.

My primary source of data is Hess (1995), which consists of a grammar, a reader, and four stories on an accompanying tape; all four texts are traditional legends told by the same consultant, Edward Sam, a speaker of the Snohomish dialect of Northern Lushootseed, recorded in the field in the early 1960s. Of the four stories, three have been analyzed for this paper using Signalyze 3.12 voice-analysis software; the examples given below come from one of these three stories - "Little Mink and his Younger Cousin, Tetyika", "Coyote and the Big Stone", and "Bear and Fish-Hawk" - and will be cited by source text and line number. Additional data has been drawn from a tape recording of the story of "Pheasant and Raven" as told by Martha Lamont (Hess, to appear), also a speaker of Snohomish; this recording was subjected to waveform and pitch-extraction analysis using WinCECIL software. In most cases data is given in phonemic transcription, except where the phonetics is at issue; similarly, interlinear glosses are in general as detailed as possible, but in some cases words are left unanalyzed when their composition is not relevant to the discussion.

\section{Phonological Phrasing}

The formation of phonological phrases $(\mathrm{PhP})$ in Lushootseed is closely tied to the notion of the phonological word, and the building of phrases in many ways resembles the building of syllables - so much so, that in the following sections I will borrow a great deal of terminology from syllabic phonology as a descriptive convention. Like the syllable, the Lushootseed phonological phrase is built up around a single head or phrasal nucleus, and the ideal or canonical phrase allows for a single initial non-head element - the phrasal onset; on the other hand, phrasing does not allow for any element to follow the head (i.e. a phrasal coda). The head of a phonological 
phrase is a phonological word (W) in the sense that it can stand on its own in a phrase and is a legitimate target for cliticization. The head of a phrase bears the unique phrasal stress as marked by amplitude and, usually, vowel length (Barthmaier 1998). As with syllabic nuclei, it is the position of the phrasal heads in the sentence that determines the associations of the various nonheads, or clitics (C), within the next-higher level units. Clitics can not be stressed and must be cliticized or affixed to a phonological word, optimally forming a CW phonological phrase.

The domain of phonological phrasing is the intonational phrase (IP), and within the IP lexical elements are parsed exhaustively into PhPs according to their status as phonological clitics or phonological words. The IP in Lushootseed is marked by pitch-contours that peak on the first full (non-schwa) vowel, whether this vowel is stressed or not; IPs may also be set off by lengthy pauses at their boundaries, although these are naturally reduced in more rapid speech. Between the PhP and the phonological word, there seems to be no evidence for a more articulated organization of the Lushootseed prosodic hierarchy. While the $\mathrm{C}+\mathrm{W}$ pattern of phonological phrasing described here is somewhat reminiscent of the behaviour of clitics in what has been called a clitic group (Nespor \& Vogel 1986; various papers in this volume), there is no evidence that these $\mathrm{C}+\mathrm{W}$ units constitute an intermediary constituent that might then be recombined into PhPs. Below the level of the $\mathrm{W}$, the absence of predictable, non-lexicalized secondary stress seems to indicate the absence of metrical feet (or, at best, argues for left-headed unbounded feet which are isomorphic with the prosodic word); by the same token, the inability of non-words to bear stress makes it difficult to argue for their being parsed into feet at all. Thus, at this stage of the game, a Lushootseed sentence appears to have the prosodic structure shown in (2): 


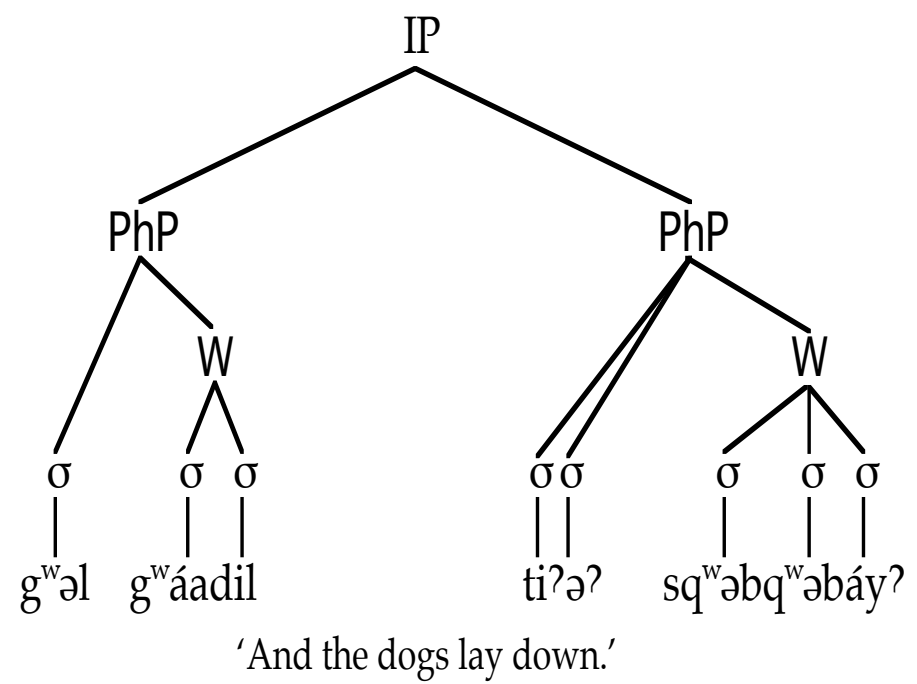

It should be noted, however, that the word-level prosodic phonology of this language awaits detailed investigation, and it seems possible that there are some intermediary domains for segmental alternations that could be used to define prosodic constituents below the word and above the syllable ( $c f$. Bianco 1995 on the behaviour of certain suffixes and, in a related language, Czaykowska-Higgins 1997). Fortunately, clarification of these issues is a bit beyond the scope of this paper, which is aimed at the processes above the word-or, more precisely, at the ways in which lexical elements are recombined into phonological phrases. What is really at stake here - and what the CW pattern outlined above and described in detail in section 2.1 serves to illustrate - is that in Lushootseed there is not a one-to-one mapping between what is treated by the syntax as a word (i.e., a morphosyntactically autonomous entity) and what is recognized as a word (the domain of phonological affixation and stress assignment) by the phonology. As we shall see in section 2.2, phonological phrasing is independent of syntactic structure, and it is the status of a lexical item as a phonological clitic or as a phonological word that counts in Lushootseed prosodic phonology.

\subsection{The Phonological Phrase}

The rules or constraints that build phonological phrases in Lushootseed are quite straightforward and, as noted above, bear a strong resemblance to the rules used to form syllables in many languages. Each phrase in Lushootseed is built up around a phonological word which serves as a 
kind of phrasal nucleus. A Lushootseed sentence can consist of a single word or a string of words, each constituting its own phrase (delimited here by parentheses), as in (3): ${ }^{1}$
(a) (?íbibəš-əx $\left.{ }^{w}\right)$
[rdp]walk-now
'he walks all around'

(Little Mink 15)

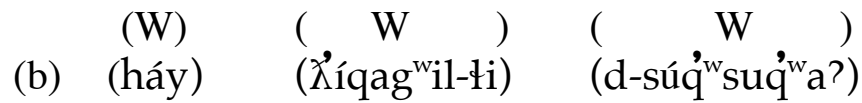 well·thencome-out-[imp] 1po-[rdp]cousin 'well then, come out of there, my cousins'

(Coyote 56)

The Lushootseed phonological phrase (PhP) is frequently set off from contiguous phrases by an audible pause, usually of approximately 50 to $100 \mathrm{~ms}$; in rapid speech this pause may be smaller, but it is usually perceptible in even these circumstances by the lack of phonological interaction between segments located on either side of a phrasal boundary. As in (3), a PhP may contain a single word, but more commonly a phrase consists of a word and one or more clitics or affixes, and in many cases constitutes an entire sentence, as in (4):

$$
\begin{aligned}
& \left(\begin{array}{ll}
\mathrm{C} & \mathrm{W}
\end{array}\right)
\end{aligned}
$$

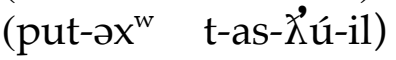

$$
\begin{aligned}
& \text { really-now [past]-[stat]-thin-[trm] } \\
& \text { 'he was really getting thin now' }
\end{aligned}
$$

(Coyote 54)

Within the phrase, the phonological nucleus bears the single stress (marked by a peak in amplitude). Thus, in (4) the unique stress falls on /u/ in the root of the verb tas خैuil 'was getting thin'; the adverb receives no stress and becomes a clitic. Phonologically, cliticization is marked by the lack of a pause between elements and, in some cases, the beginnings of coarticulatory assimilation at the word-clitic boundary.

\footnotetext{
${ }^{1}$ The abbreviations used here are: $1,2,3=$ first-, second-, third-person; add $=$ additive; appl $=$ applicative; $\mathrm{C}=$ phonological clitic; caus = causative; $\mathrm{D}=$ deictic; $\mathrm{IP}=$ intonational phrase; intj = interjection; irr $=$ irrealis; 1.o.c. $=$ lack of control; $\mathrm{md}=$ middle; neg = negative; $\mathrm{np}=$ nominalizing prefix $; \mathrm{p}=$ plural; $\mathrm{PhP}=$ phonological phrase; $\mathrm{pnt}=$ punctual $;$ o $=$ possessive; prog $=$ progressive $;$ prt $=$ particle $; r d p=$ reduplication $; \mathrm{s}=$ singular $;$ stat $=$ stative $;$ subj $=$ subjunctive; top = topic-marker; trm = transmutative; $\mathrm{W}=$ phonological word. Boundaries are marked by: $\S=$ intonational phrase; $)($ = phonological phrase; + = phonological affix; $-=$ morphological affix $][$ = syntactic phrase.
} 
When sentences get more complex, they consist of more than one phrase, each containing a single word, and optimally a single clitic as in (5):

$$
\begin{aligned}
& \left(\begin{array}{lll}
\mathrm{C} & \mathrm{W}
\end{array}\right) \quad\left(\begin{array}{ll}
\mathrm{C} & \mathrm{W}
\end{array}\right) \\
& \text { (a) (ti?ił sbíaw) (gw ? ?úx } \left.\check{x}^{\mathrm{w}}-\mathrm{gx}^{\mathrm{w}}\right) \\
& \text { D coyote [top] go-now } \\
& \text { 'this Coyote, [he] goes along' } \\
& \left(\begin{array}{lll}
\mathrm{C} & \mathrm{W}
\end{array}\right) \quad\left(\begin{array}{ll}
\mathrm{C} & \mathrm{W}
\end{array}\right) \quad\left(\begin{array}{ll}
\mathrm{C} & \mathrm{W}
\end{array}\right)
\end{aligned}
$$

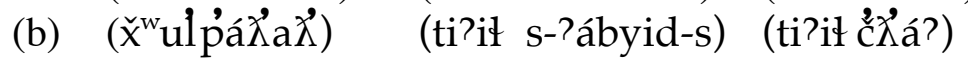

$$
\begin{aligned}
& \text { only worthless D np-give-3po D stone } \\
& \text { 'what he gave to Stone [was] only junk' }
\end{aligned}
$$

(Coyote 45)

(Coyote 32)

As these examples show, the preferred phrasal pattern is one of procliticization, with a preceding clitic joining to a word to form a sort of phrasal "onset". Words never cliticize to words or share clitics between them. This is also apparent in (6), which shows that when a $\mathrm{C}$ appears between two Ws, it adjoins to its right rather than to its left:
$\left(\begin{array}{cc}\mathrm{C} & \mathrm{W}\end{array}\right)$
( C
W
)$(\mathrm{C}$
W )
(W)
(ti?ił ?áciłtalbix ${ }^{w}$ ) (tuul?al
people
from
bákw $\left.{ }^{\mathrm{w}}\right) \quad($ čád)
all where
(a) (huy q $^{w}$ ú?-t-əb-əx ${ }^{w}$ )
then gather-[caus]-[md]-now
'then the people were gathered together from everywhere'
(Little Mink 47)
(W)
( C
W
(W)
(W)
(W)
(b) (háy) (čəd łu-yəc-əb-tú-bicid-əxw ${ }^{w}$ (dəgwí (sí?ab) (d-syá?ya?)
well-then 1s [irr]-tell-[md]-[caus]-2s-now $2 \mathrm{~s}$ noble 1po-friend
'well then, I will tell [it] to you now, my noble friend'

(Little Mink 4)

In terms of a model, the patterns observed up to now could be handled either by some sort of association rule linking clitics rightward to the nearest head before linking them leftward, or, alternatively, could be described in terms the ranking of various constraints on phrase-formation in the style of Optimality Theory (OT-Prince \& Smolensky 1993). Given that my aim here is to describe the patterns found in the data rather than to develop a rigorous theoretical apparatus, I will informally opt for the latter as a descriptive convention, without going to great lengths to justify it in detail. For the same reason, I will not make use of what are currently the standard OT 
alignment constraints or try to position this work with respect to relevant theoretical issues current in the OT literature. Such activities are left to the interested reader. For our purposes here all we need is a set of simple constraints, beginning with one stating a preference for phrasal “onsets" over phrasal "codas", which I will dub in the OT spirit "No PhP-Coda" (NPC):

(7) No PhP-Coda (NPC)

A phrase must not contain an enclitic following the phrasal nucleus.

This prevents non-words from becoming enclitics. Similarly, there must be a constraint governing phrasal onsets, though what this might consist of is not yet apparent.

So far, all of the examples shown have been cases with alternating CW patterns. However, clitics often occur adjacent to one another as well, as in (8):
(a) [(ti?ił bíbščəba)
$/($ ti?ił bibščəb+?i)
(ti?ił sú?suqwa?s)] ...
D [rdp]mink+and D [rdp]cousin-3po
'Little Mink and his cousin ...'
$\left(\begin{array}{l}\mathrm{W}+\mathrm{C}\end{array}\right) \quad\left(\begin{array}{ll}\mathrm{C} & \mathrm{W}\end{array}\right)$
(b) [(tud ${ }^{z}$ əláx̌adbidəl) (ti?ił pádṫos) $]$
/(tu-dzalax̌adbid+?al) (ti?ił pəd’̉̇s)/
[past]-visit+on D winter
'[he] went to visit [him] in the winter'

(Little Mink 5)

(Bear \& Fish-Hawk 5)

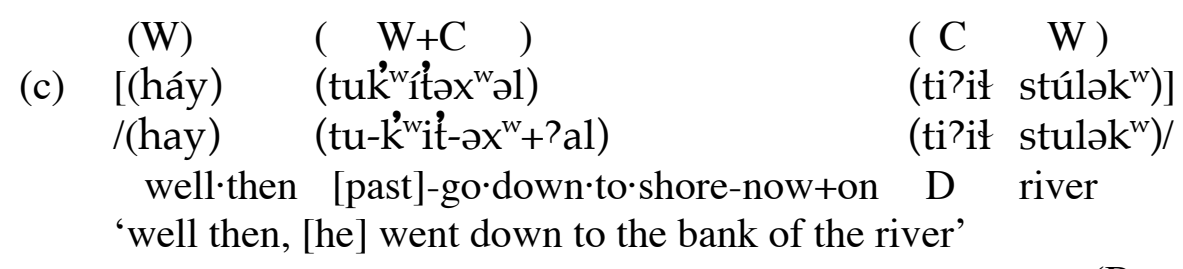

(Bear \& Fish-Hawk 10)

While these sentences appear to be violations of the constraint against phrasal codas, in each of these cases the first clitic in a WCCW string has, in fact, been parsed into the preceding phrase, not as an enclitic, but as an affix (shown by the “+”). Affixation or phonological incorporation can be distinguished from cliticization in that where ordinary clitics generally retain their own shape and original segmental material, an incorporated clitic re-syllabifies with a stem and, in 
most cases, either loses a mora or some phonemic material, or triggers some phonological alternation such as consonant or schwa-deletion in the word to which it attaches-all of which are processes typical of Lushootseed word-level phonology ( $c f$. the reduction of the past-time prefix /tu-/ to [t-] in (4) above). In all of the examples in (8), the incorporated clitic loses its onset, becomes a part of the final syllable of the preceding word, and undergoes vowelreduction, $/ \mathrm{i} />[\ni]$ in (a) and $/ \mathrm{a} />[\mathrm{\partial}]$ in (b) and (c). Other examples offer even more striking evidence for affixation:

(9)

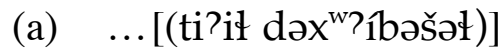
.../(ti?ił dəx ${ }^{\mathrm{w}}-$ - ibəšččł $) /$
D np-walk+1p.po
'... for our journey' (utterance-final)

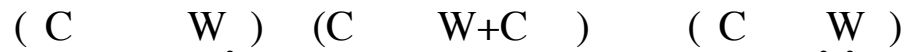

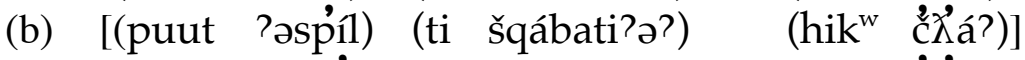
/(puut ?əs-p̉il) (ti šq-abac+ti?ə?) (hik ${ }^{\mathrm{w}}$ č̉̉a?)/
really [stat]-flat D high-body+D big stone
'it [was] really flat up on top of the big stone'

(Coyote 10)

(Coyote 4)

Here incorporated clitics - in (a) the possessive pronominal čət 'our' and in (b) the deictic ti? ${ }^{2}$ ?-lose onsets somewhat more substantial than a glottal stop and are resyllabified with their phrasal head; in (b) the final consonant in šqabac undergoes deaffrication $([\mathrm{c}]>[\mathrm{t}])$. In (10), the possessive pronominal /čəł/ seen in (9a) loses its syllabic nucleus and is reduced to [čł]:

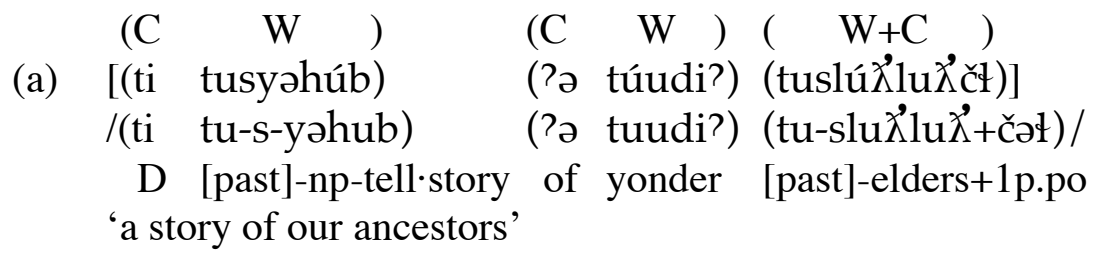

(Little Mink 2)
( C
$\mathrm{W}+\mathrm{C} \quad)$
(b) $[($ dił
dəx ${ }^{\mathrm{w} u ́ t a s a d c ̌ l}$ )
$\left(\begin{array}{ll}\mathrm{C} & \mathrm{W}\end{array}\right)$
$/(\mathrm{di}$
dəx ${ }^{\mathrm{w}}-\mathrm{?} \mathrm{u}$-tasa-d+čət)
(ti?ə? čX̉á?)]
(ti?ə? čx̉a?)/
[focus] np-[pnt]-paid-[caus]+1p.po D stone
'this [is] why we are paying Stone'

(Coyote 11) 
The next example contains two instances of affixation:

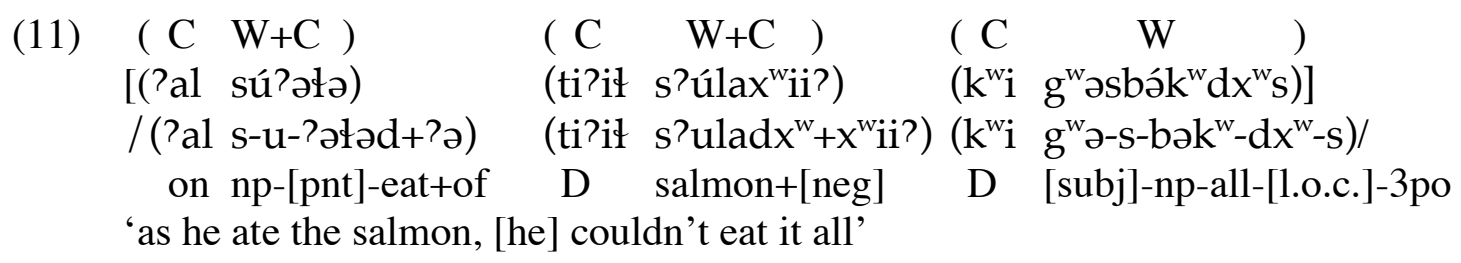

(Bear \& Fish-Hawk 23)

In the second case, the onset of the incorporated clitic $\check{x}^{w i i}$ ? '[neg]' assimilates to the final

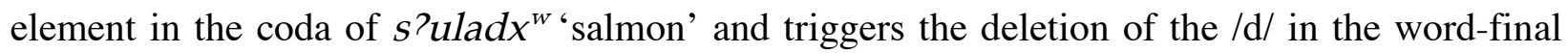
coda of its head, as does the preposition ?ə in su?əłə, derived from /s?ułəd+?ə/. There are a number of other boundary phenomena associated with incorporation, and while there is by no means enough space to go into all of them here, a few more will be dealt with in the context of prefixation, which provides an even clearer contrast between affixation and cliticization. For the moment it is enough to note the distinctive behaviour of affixes as opposed to clitics: in the former there is a high degree of phonological incorporation, whereas in the latter the clitic more closely resembles its citation form.

Because a single clitic is a legitimate phrasal onset, proclitics are not normally incorporated, whereas enclitics are inevitably so. If the enclitic is treated as a suffix and hence part of the word forming the phrasal head, the result is a fairly consistent pattern of CW phrases. In terms of constraints, this indicates that there is a requirement that phrasal onsets contain one and only one cliticized element, thereby forcing a phrase boundary between the clitics in a WCCW sequence. I will refer to this constraint as "Single Phrasal Onset" (SPO):

(12) Single Phrasal Onset (SPO)

A well-formed phrase will contain a single clitic preceding the phrasal nucleus.

In addition, there must be a constraint (or pair of ranked constraints) preferring suffixation over prefixation, to prevent the creation of $(\mathrm{C} \mathrm{W})(\mathrm{C} \mathrm{C}+\mathrm{W})$ strings in situations like (11), and we also need a constraint forcing clitics to be associated with phrasal heads and preventing the cliticization of clitics to other clitics: 


\section{(13) PARSE}

Clitics must be linked to a proper phrasal head (a phonological word).

This serves to prevent two clitics joining together either to form a phrasal nucleus or to form a single unit which could constitute a complex phrasal onset $($ i.e. $(\mathrm{C}+\mathrm{C} \mathrm{W}))$. Finally, we need a constraint governing affixation, one which would be ranked below both NPC (hence, suffixation takes place over encliticization) and SPO. I will refer to this constraint as "Don't Incorporate" (DI):

(14) Don't Incorporate (DI)

$* \mathrm{C}+\mathrm{W} ; * \mathrm{~W}+\mathrm{C}$

This is a simple prohibition against phonological incorporation, in the spirit of the faithfulness constraints proposed by McCarthy \& Prince (1993), which work to preserve the underlying form of a phonological string.

\subsection{Clitic Sequences within Phrases}

In the previous section we examined data where the input to the phonology consisted of sentences with strings of no more than two consecutive clitics potentially separable by a phrase boundary. Sometimes, however, the grammar creates sequences of two or more clitics which can not be divided into separate phrases. In some cases, usually when the position of the "stray" clitic corresponds to an IP boundary, it is deleted:

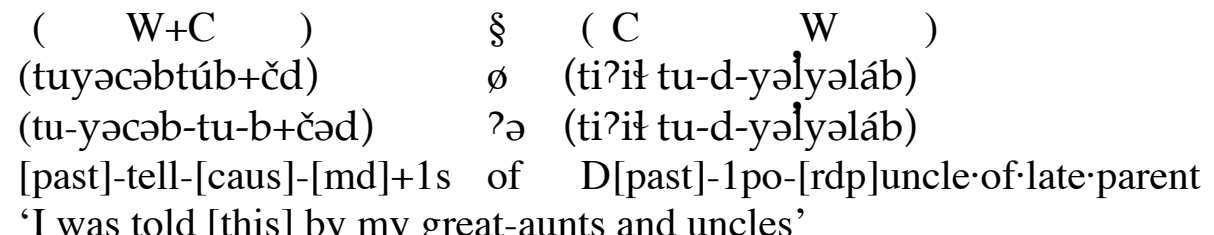

(Little Mink 3)

Grammatically this sentence, a passive, requires the preposition ? 2 marking the oblique agent; in the utterance on tape, this particle does not surface, possibly having been "erased" by its failure to associate with a phrasal nucleus. It should be noted, however, that this is not a very wellattested phenomenon and may be attributable to speaker error. A more common strategy for 
dealing with this sort of situation is seen in (16), where the addition of an element as a proclitic causes the incorporation of the next element closer to the head as a prefix:

\begin{tabular}{|c|c|c|c|}
\hline \multirow{4}{*}{ (a) } & & & \\
\hline & {$\left[\left(\mathrm{x}^{\mathrm{w}} \mathbf{i}\right)\right.$} & $\mathrm{k}^{\mathrm{w}} \mathrm{ik}{ }^{\mathrm{w}}$ adsukáwdx ${ }^{\mathrm{w}}$ ) & (ti?ił scáli?)] \\
\hline & $/\left(\mathrm{x}^{\mathrm{w}} \mathrm{i}\right.$ ? & $\left.\mathrm{k}^{\mathrm{w}} \mathrm{i}+\mathrm{g}^{\mathrm{w}} 2-\mathrm{ad}-\mathrm{s}-? \mathrm{u}-\mathrm{k}^{\prime} \mathrm{w}-\mathrm{d} \mathrm{x}^{\mathrm{w}}\right)$ & (ti?ił scali?)/ \\
\hline & $\begin{array}{l}{[\mathrm{neg}]} \\
\text { 'don't }\end{array}$ & $\begin{array}{l}\mathrm{D}+[\text { subj]-2po-np-chew-[1.o.c. } \\
\text { chew on [my] heart' }\end{array}$ & D heart \\
\hline
\end{tabular}

(Little Mink 19)

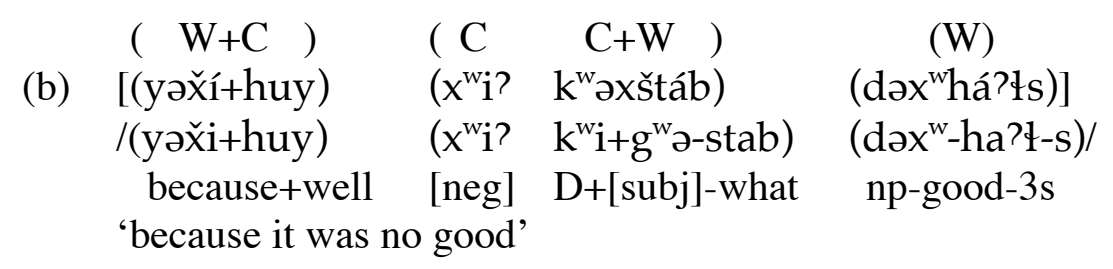

(Coyote 31)

$$
\begin{aligned}
& \left(\begin{array}{ll}
\mathrm{W}+\mathrm{C}
\end{array}\right) \quad\left(\begin{array}{ll}
\mathrm{C} & \mathrm{C}+\mathrm{W}+\mathrm{C})(
\end{array}\right) \\
& \text { (c) }\left[\left(\text { hík }^{\mathrm{w}}+\text { ə⿳亠丷厂 }\right) \quad\right. \text { (qa tíišədə) (ti?ił sbíaw) } \\
& \text { /(hik }{ }^{\mathrm{w}}+\text { วw’ว) (qa ti?ił+?iišəd+?ə) (ti?ił sbiaw)/ } \\
& \text { big }+ \text { [surprise] many D+relatives+of D coyote } \\
& \text { 'the relatives of Coyote really [are] very many' }
\end{aligned}
$$

(Coyote 64)

Incorporation takes place at sentence boundaries and in strings where there would otherwise be three-clitic sequences; thus, WCCCW is parsed as $(\mathrm{W}+\mathrm{C})(\mathrm{C} \mathrm{C}+\mathrm{W})$. Just as in suffixation, a number of boundary phenomena can be observed at work marking the phonological incorporation of the clitic-cum-affix into the word: in (16a) we have $/ \mathrm{k}^{\mathrm{w}} \mathbf{i} \mathrm{g}^{\mathrm{w}} \mathrm{\partial}-\mathrm{ads}$ ? $\mathrm{ukawdx}^{\mathrm{w}} /$ collapsing into

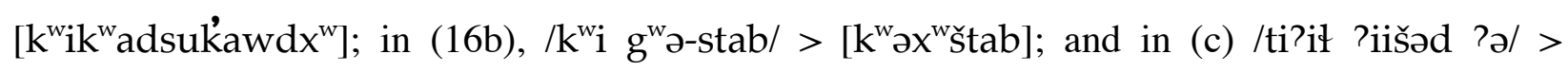
[tiišədə]. Compare this last example with the phrasing in (17):

$$
\begin{aligned}
& \text { (W) } \quad\left(\begin{array}{lll}
\mathrm{C} & \mathrm{W}
\end{array}\right) \quad\left(\begin{array}{ll}
\mathrm{C} & \mathrm{W}
\end{array}\right)
\end{aligned}
$$

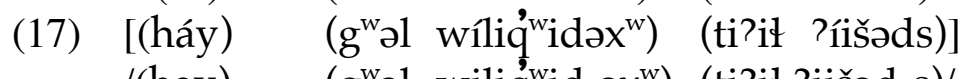

$$
\begin{aligned}
& \text { /(hay) (gwal wiliq } \left.{ }^{w} i d-\partial x^{w}\right) \text { (ti?ił ?iišəd-s)/ } \\
& \text { well-then intj ask-now D relative-3po } \\
& \text { 'well then [he] asked his relatives' }
\end{aligned}
$$

(Coyote 5)

Here there is no incorporation of the deictic to the following word, and the clitic retains all of its phonological material. 
In terms of our constraint-based analysis, this behaviour must be accounted for by the interaction of the constraint hierarchy. Clearly, if both NPC (which prohibits phrasal codas) and SPO (which governs the well-formedness of phrasal onsets) dominate DI, then a string of proclitics would be a violation of a higher-ranked constraint (SPO, which requires a single proclitic as the phrasal onset) than is affixation of one of the clitics to a word (which violates only DI); the action of these three constraints along with the constraint against cliticization to a clitic (PARSE) seems to fully describe the behaviour of clitics in CCC environments, as in (18):

(18) Input: [WCCCW]

\begin{tabular}{||lc||c:c:c|c||}
\hline & Candidates & NPC & SPO & PARS & DI \\
\hline \hline a. & $\mathrm{W} \mathrm{C})(\mathrm{C} \mathrm{C}+\mathrm{W}$ & $* !$ & & & $*$ \\
\hline b. & $\mathrm{W}+\mathrm{C})(\mathrm{C} \mathrm{C} \mathrm{W}$ & & $* !$ & & $*$ \\
\hline c. & $\mathrm{W}+\mathrm{C}+\mathrm{C})(\mathrm{C} \mathrm{W}$ & & & $* !$ & $* *$ \\
\hline d. & $\mathrm{W})(\mathrm{C} \mathrm{C}+\mathrm{C}+\mathrm{W}$ & & & $* !$ & $* *$ \\
\hline e. & r & & & \\
\hline
\end{tabular}

It would also be interesting to find sentences which contain strings of more than three phonological clitics, but so far these are not attested in the data. For my purposes here, it has been enough to show that phonological phrases in Lushootseed follow a straightforward pattern captured in terms of a few simple constraints, and that the $\mathrm{PhP}$ is describable under most circumstances in purely phonological terms.

\section{Phonological versus Syntactic Phrasing}

Up until this point we have been treating phrasing in Lushootseed as a phonological matter, looking at strings of clitics and words with no attention being paid to underlying syntactic or semantic structures. The result of this analysis has been an informal constraint-based description of the behaviour of elements in strictly phonological terms; this treatment has successfully accounted for the data so far, but has begged the question of what relationship might hold between the $\mathrm{PhP}$ and syntactic structure, and whether this phonological phrasings might have some underlying syntactic motivation. In fact, the phonological phrasing of a Lushootseed sentence seems to have little relation to either constituent- or dependency-based divisions in 
syntactic structure: rather than grouping words into syntax-based units, phrase boundaries can and often do cross constituent boundaries and a wide variety of syntactic dependency types. In (19), for instance, a PhP boundary intervenes between a prepositional head and its DP complement (a P $\rightarrow$ DP dependency).

$$
\begin{aligned}
& \left(\begin{array}{l}
\mathrm{W}+\mathrm{C} \\
(\mathrm{C} \quad \mathrm{W})
\end{array}\right.
\end{aligned}
$$

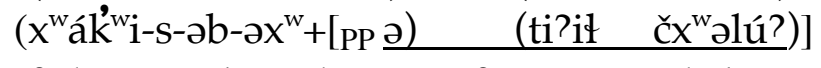

$$
\begin{aligned}
& \text { fed-up-[appl]-[md]-now+of D whale } \\
& \text { 'Whale got fed up [with them]' } \\
& \text { (lit. 'they were gotten fed up with by Whale') }
\end{aligned}
$$

(Little Mink 11)

In (20), the phrase boundary cuts across a DP, separating a complex NP from its head (crossing a $\mathrm{D} \rightarrow \mathrm{NP}$ dependency).

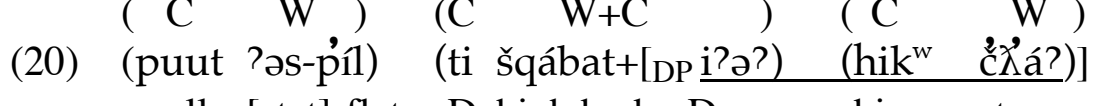

$$
\begin{aligned}
& \text { really [stat]-flat D high.body+D big stone } \\
& \text { 'it [was] really flat up on top of the big stone' }
\end{aligned}
$$

(Coyote 4)

In the same spirit, $\mathrm{PhP}$ boundaries cut across VPs, separating verbs from adverbs ( $\mathrm{V} \rightarrow \mathrm{Adv})$ :

$$
\begin{aligned}
& \text { (21) (?u [vp túx } \left.\check{x}^{w}\right) \text { (čəd ?u-?íbibəš)] } \\
& \text { [intj] only 1s [pnt]-[rdp]walk } \\
& \text { 'I am just walking around' }
\end{aligned}
$$

(Little Mink 18 \& 26)

They may also separate conjunctions from a following DP (Conj $\rightarrow$ DP), as in

$$
\begin{aligned}
& \left(\begin{array}{lll}
\mathrm{C} & \mathrm{W}+\mathrm{C}
\end{array}\right) \quad(\mathrm{C} \quad \mathrm{W} \quad) \\
& \text { (ti?ił bíbščəb+[a) (tîił sú?suqwa?+s)] ... } \\
& \text { D [rdp]mink+and D [rdp]cousin-3po } \\
& \text { 'Little Mink and his cousin ...' }
\end{aligned}
$$

(Little Mink 5)

Phrase boundaries can also combine parts of syntactic phrases which are quite distant from one another in a syntactic tree, as in (23) where the prepositional head of the right member of a paratactic conjunction is paired with the final NP of the left member (recall that $\S$ marks an IPboundary): 


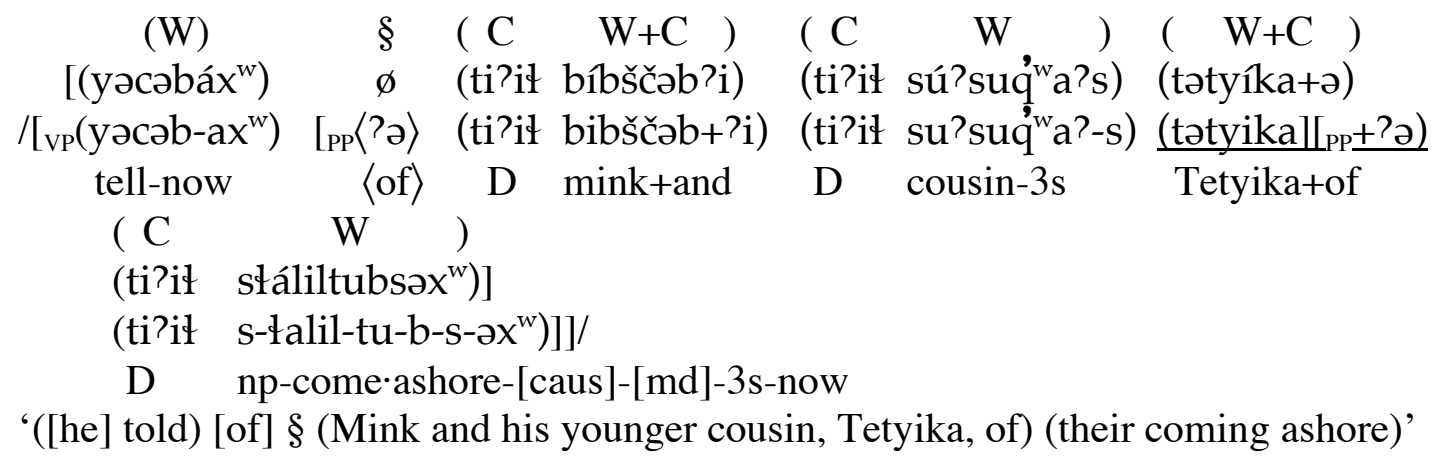

(Little Mink 42)

Clearly, then, issues of constituency or dependency do not play a direct role in the formation of phonological phrases, at least in the sense that a phonological phrase should conform to a syntactic constituent or to a dependency sub-tree.

The examples given so far, however, could be construed as evidence for another kind of syntax-based phrasal metric, something along the lines proposed in Chen (1987), which associates the appearance of a particular phrasal boundary - Right or Left - with a certain node - X-head or $\mathrm{X}$-max - of a phrase-structure tree. In the examples here, it appears that the right phrasal boundary coincides more or less with the appearance of a syntactic head, which might lead us to posit a Chen-like parameter X-HEAD RIGHT. This view is reinforced by the behaviour of DPs, which (à la Cowper \& Rice 1987) form a single phrase when the D governs a simple NP, as in (19) (a phrasal boundary having been set after the PhP head) but which are divided when the NP is complex, as in (20). However, X-HEAD RIGHT runs into some trouble with the VP in (21), where an adverbial modifier-which is not the syntactic head of anything - has been made the phonological head of a phrase and consequently separated from its verb, which is the syntactic head and should thus have determined the location of the phrasal boundary. While this might be resolved by invoking various kinds of movement (which would be needed by a phrase-structure grammar to account for the linear order of the sentence elements, since the subject pronominal should appear higher in the tree than the adverb), matters are further complicated by the fact that verbs are grouped together with adverbs when no other clitics intervene: 


$$
\begin{aligned}
& \left(\begin{array}{lll}
\mathrm{C} & \mathrm{W}+\mathrm{C}
\end{array}\right) \quad\left(\begin{array}{ll}
\mathrm{C} & \mathrm{W}
\end{array}\right) \\
& \text { ( } \\
& \text { completely [pnt]-finish-[1.o.c.]-[md]+of D whale } \\
& \text { 'that was the end of Whale' }
\end{aligned}
$$

(Little Mink 29)

VPs also present difficulties in sentences like (25):

$$
\begin{aligned}
& \left(\begin{array}{ll}
\mathrm{W}+\mathrm{C}
\end{array}\right) \quad\left(\begin{array}{lll}
\mathrm{C} & \mathrm{C}+\mathrm{W}+\mathrm{C}
\end{array}\right)\left(\begin{array}{ll}
\mathrm{C} & \mathrm{W}
\end{array}\right) \\
& \text { (hík } \left.{ }^{\mathrm{w}}+\text { əəwว }\right) \text { (qa ti?ił+?íišəd+?əa) (ti?ił sbíaw) } \\
& \text { big }+ \text { [surprise] many D+relatives+of D coyote } \\
& \text { 'the relatives of Coyote really [are] very many' }
\end{aligned}
$$

(Coyote 64)

In (25) the head of the VP-the adverb qa 'many'-cliticizes to the following NP instead of causing the predicted insertion of a phrase boundary immediately to its right.

A further difficulty for predicting phrase boundaries with X-HEAD RIGHT is found in examples like those in (26), where - as in (21) - a phonological head is by no means a syntactic head.

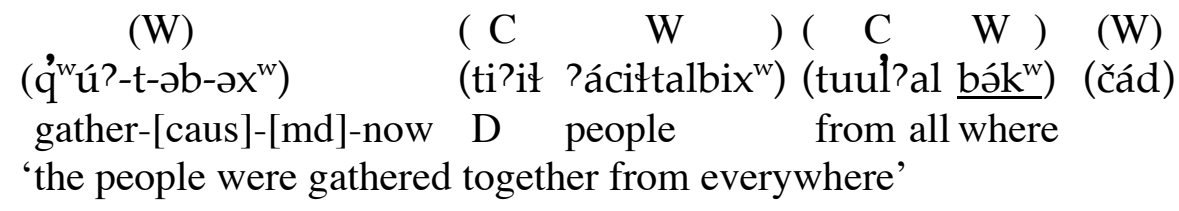

(Little Mink 47)

The same problem arises when a phrase cuts across sentences in rapid speech:

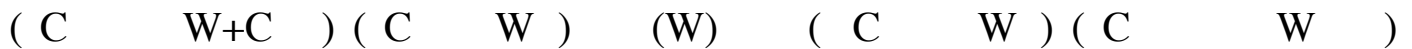

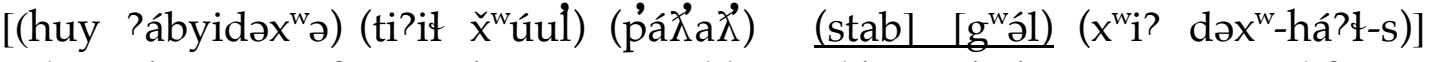
then give-now+of $D$ just worthless thing intj [neg]np-good-3s 'then [he] gave [him] a totally worthless thing. Well, it was no good'

(Coyote $17-18)$

In situations such as this, it is difficult to see how a particle like $g^{w} \partial l$ (its function here being more or less that of an interjection like "well") can be taken as the syntactic head of the following phrase. Once again, the problems may not be insurmountable, but one starts to wonder at the utility of a syntactic explanation when a much more straightforward phonological analysis is at hand. 


\section{Words and Clitics}

The thrust of the argument up to this point has been that, given the characterization of a sequence of lexical items as Ws or Cs, it is possible to predict (within the boundaries of a given IP) how this sequence will be divided into phonological phrases; the proper characterization of lexemes as words or clitics has merely been assumed. As it turns out, however, this issue is not an entirely simple one, and, although certain generalizations can be made about whether a given lexical item will be treated prosodically as a word or as a clitic based on its lexical class, in many instances the treatment of a given item will vary depending on its prosodic environment.

As in other Salishan languages, Lushootseed words are often divided into predicative and non-predicative classes (Kinkade 1983; van Eijk \& Hess 1986), and to a certain extent this division is reflected in the phonology, in that the former tend to be treated prosodically as heads. Predicative words, as their name indicates, can function as sentence predicates (underlined) as in (28):

$$
\begin{aligned}
& \text { (28) (a) } \frac{\text { s?úladx }}{\text { salmon }} \text { ti?ił } \\
& \text { 'that [is] a salmon' } \\
& \text { (b) lə-q’ád čəd } \\
& \text { [prog]-slow 1s } \\
& \text { 'I [am going] slow } \\
& \text { (c) túdi? to dúk wibəł } \\
& \text { yonder DChanger } \\
& \text { 'Changer [is] way over yonder' } \\
& \text { (d) sáli? ti?ə? sq } \text { sqúg }^{\mathrm{w}} \mathrm{ac} \\
& \text { two D deer } \\
& \text { 'the deer [are] two' }
\end{aligned}
$$

(Hess \& Hilbert 1976: I, 7)

(Bates et al. 1994: 183)

(Hess 1993: 103)

(Hess 1993: 103)

Non-predicative words, often termed "particles", on the other hand, can not serve as the predicate of a sentence and must be associated syntactically with a predicative element. In terms 
of lexical meaning, predicative words are, for the most part, "content" words, whereas many of those words which are strictly non-predicative are functional grammatical elements.

In the phonology, the rule of thumb is that predicative words act as phrasal heads (i.e., are words) while the others adjoin either rightward or leftward to full words within the phrase boundary. This generalization captures nicely the behaviour of words such as nouns and derived verbs, and of non-predicative elements such as pronominals, prepositions, and interjections. Outside of these groups, however, things get more complicated. Deictic markers, for instance, are potential predicates and are syntactic heads (Jelinek 1993; Matthewson \& Davis 1995; Beck 1997), but are apparently not phonological heads, even when they are syntactic predicates, as in (29):

$$
\begin{aligned}
& \text { ( } \mathrm{C} \quad \mathrm{C}+\mathrm{W} \text { ) } \\
& \text { (ti?ił ti+s? úladx }{ }^{w} \text { ) } \\
& \text { D D+salmon } \\
& \text { 'a salmon [was] this one' }
\end{aligned}
$$

(Bear \& Fish-Hawk 57)

Here both deictics surface as clitics, just as they do in other syntactic environments. ${ }^{2}$

In addition, there are a large number of predicative words which are variable in terms of their status as clitics or phonological words. Words corresponding to English adverbs, for instance, can be subdivided morphosyntactically into adverbial particles and true adverbs. The adverbial

\begin{tabular}{|c|c|}
\hline $\operatorname{cick}^{w}$ / cay & very \\
\hline $\mathrm{ck}^{\mathrm{w}}$ aqid & always \\
\hline $\mathrm{da}^{2} \mathrm{x}^{\mathrm{w}} /$ daw & just now \\
\hline dəx $x^{w}$ & [?] \\
\hline$g^{w} a^{2} x^{w}$ & eventually, soon \\
\hline put & very much so, in a great way \\
\hline tiləb & immediately, bluntly; right there \\
\hline$\check{x}^{w} \partial ł t i$ & as though, like \\
\hline$\check{x}^{\mathrm{w}} \mathrm{ul}$ & just (that and nothing else) \\
\hline
\end{tabular}
particles, shown in (30), can not be predicative, nor can they be phonological heads.

Lushootseed adverbial particles

\footnotetext{
${ }^{2}$ See, however, (34) below, where the deictic tudi? 'yonder' surfaces as a phonological word when given emphatic length and amplitude; see also the discussion of deictics in topic-setting structures in (35).
} 
True adverbs, on the other hand, are both modifiers of verbs (and, in some cases, of nouns) and potential sentence predicates, and are eligible phonological heads. These are given in (31):

(31) Lushootseed adverbs

\begin{tabular}{|c|c|c|c|}
\hline 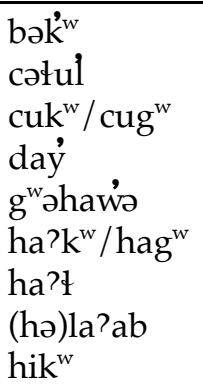 & $\begin{array}{l}\text { all } \\
\text { previously, in advance } \\
\text { only, uniquely } \\
\text { only, uniquely, totally } \\
\text { it seems } \\
\text { ago, long time } \\
\text { well, good } \\
\text { really, a lot } \\
\text { big, very }\end{array}$ & 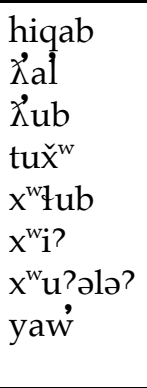 & $\begin{array}{l}\text { excessively, too (much) } \\
\text { also, too } \\
\text { well; ought, should } \\
\text { in contrast to the expected } \\
\text { ultimately, in fact } \\
\text { no, not } \\
\text { maybe, perhaps } \\
\text { only if, not until }\end{array}$ \\
\hline
\end{tabular}

Whether or not the adverbs in (31) are realized as clitics or as phonological words, however, is entirely a matter of phonological necessity - that is, the clitic/word status of these elements depends not on whether the adverb functions as a syntactic predicate, but on which phonological realization, $\mathrm{C}$ or $\mathrm{W}$, is needed to best preserve the ideal $(\mathrm{C} \mathrm{W})$ phrasal template. This is shown in (32), where the adverb hik 'big' occupies the same syntactic role in both (a) and (b), but is realized in one example as a phonological clitic and in the next as a phonological word:

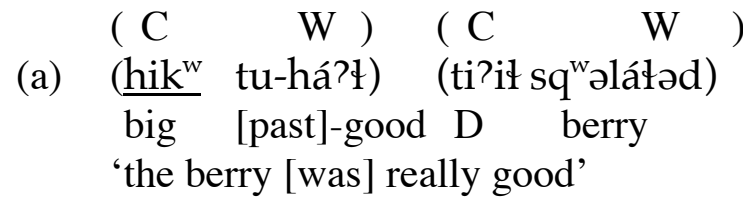

(Bear \& Fish-Hawk 30)
(b) $\left(\underline{h i ́ k}^{\mathrm{w}}+\partial w \dot{2}\right) \quad$ (qa ti?ił+?íišəd+?ə) (ti?ił sbíaw) big+[surprise] many D+relatives+of D coyote 'the relatives of Coyote really [are] very many'

(Coyote 64)

In both sentences $h i k^{W}$ acts as a sentence-initial adverb, modifying the syntactic predicatetuha?f 'good' in (a) and qa 'many' in (b)) - yet in (a) hik ${ }^{w}$ is realized as a clitic whereas in (b) it is a phonological head and takes an adverbial particle as an enclitic. Note also the status of $q a$ 'many' in (b), where this word-always a phonological clitic-acts as syntactic predicate of the sentence.

Also variable in terms of phonological status are certain adverbials of motion: 


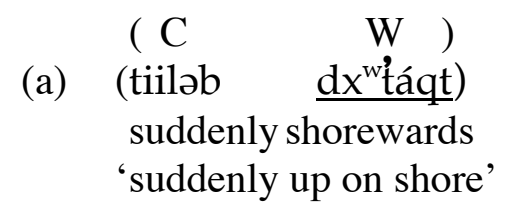

(Little Mink 31)

$$
\begin{aligned}
& \left(\begin{array}{lll}
\mathrm{W}+\mathrm{C} & )
\end{array}\left(\begin{array}{ll}
\mathrm{C} & \mathrm{W}
\end{array}\right)\right. \\
& \text { (b) }\left(\mathrm{saq}^{\mathrm{w}}+\underline{\mathrm{d} x}^{\mathrm{w}} \text { šáq) (ti?ił '́ć́x́ćī̌ }\right) \\
& \text { fly+up.high D fish-hawk }
\end{aligned}
$$

(Bear \& Fish-Hawk 11)

Many of these items are morphologically complex - being composed of a prefix $d x^{W}$ - and a locative root - which rules out the idea of defining the phonological word in terms of some kind of morphonological complexity, just as the bisyllabicity of some particles like ckaqid 'always' argues against a similar notion of phonological complexity.

The issue is clouded even further by a few examples where the phonological status of a word is manipulated for pragmatic purposes: there are a few examples of interjections, adverbial deictics, and adverbial particles standing on their own as words or acting as phrasal heads, usually accompanied by increased length and/or relative amplitude. This is seen in the emphatic lengthening of the adverbial particle $\check{x}^{w} u l$ 'just, totally' in (27) above and of tudi? 'yonder' in (34):

$$
\begin{aligned}
& \left(\begin{array}{llll}
\mathrm{C} & \mathrm{W}
\end{array}\right) \quad(\mathrm{C} \quad \mathrm{W}) \quad(\mathrm{W}+\mathrm{C}) \\
& \text { (ti tu-s-yəhúb) (?ə túudi?) (tu-slúX̊luX̃+čł) } \\
& \mathrm{D} \text { [past]-np-tell-story } \mathrm{P} \text { yonder [past]-elders+1p.po } \\
& \text { 'a story of our ancestors' }
\end{aligned}
$$

(Little Mink 2)

Although there are fewer than a handful of examples in the corpus, it may well be that this phenomenon is an active one in the phonology, particularly given its expressive power in terms of encoding focus and emphasis on particular aspects of an utterance that might not be accessible to focus by syntactic means such as topic-fronting or predication. Seen in this light, the notion of 
phonological word "formation" as an addition to Selkirk's (1995) inventory of prosodic strategies for manipulating the information structure of a sentence is an intriguing one. ${ }^{3}$

Another case where pragmatic or discourse-related factors seem to play a role in determining whether or not an element is treated as a phonological word or as a clitic is found in sentences such as those shown in (35), which serve to set the topic for an ensuing stretch of discourse: ${ }^{4}$

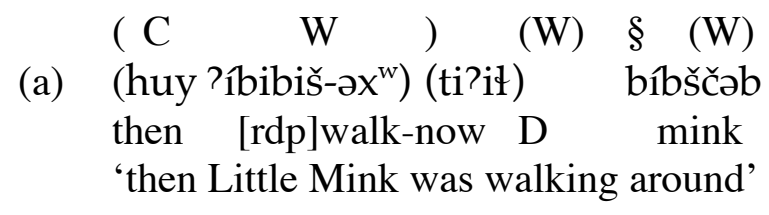

(Little Mink 14)

(W) (W) $\S(\mathrm{W}+\mathrm{C})(\mathrm{C} \quad \mathrm{W} \quad) \quad(\mathrm{W})$

(b) (?u-łî́dab) (ti?ił) (bíbščəb+ə) (ti?ił sú?suq'wa?-s)(tətyika)

[pnt]-troll D mink+and D cousin-3po Tetyika

'Little Mink and his cousin went trolling for fish'

(Little Mink 6)
(W)
(c) (háy)
(W)
well-then win-[1.o.c.]-[md]
(W) $\S\left(\begin{array}{ll}\mathrm{W}+\mathrm{C} & )(\mathrm{C} \quad \mathrm{W}\end{array}\right)$
('cəl-dú-b)
(ti?ił)
(sčátxəd+a)
(ti?a?
cícix̌)
'and so then was Bear defeated by Fish-Hawk'

(Bear \& Fish-Hawk 93)

This is a very specific construction found in a particular pragmatic domain, the beginning of a discourse episode. The sentential theme, which has been isolated from the rest of the sentence by the IP-boundary $(\S)$ and given emphasis with loudness and sometimes vowel length, must also be the syntactic subject of the sentence it appears in and, generally, of all the sentences that follow it within that episode. Thus, in (35a) and (b) bíbščəb 'Little Mink' is identified by the intonational boundary as a focalized theme and becomes the discourse topic of the ensuing episode. From a phonological point of view, these sentences are interesting in two respects: one is, of course, the insertion of the IP-boundary between the deictic and its NP; the second is the lack of

\footnotetext{
${ }^{3}$ Note, however, that emphatic lengthening does not always result in the lengthened element being treated as a word, as shown by the particle put 'very, greatly' in the example in (9b) or by the preposition tul'al 'from' in (6a)/(26). Clearly, this phenomenon merits some further investigation.

${ }^{4}$ For a discussion of Lushootseed discourse and the function of topic-setting sentences, see Beck (1996a). For a more general discussion of such structures in English and Chinese, see Pu \& Prideaux (1994).
} 
incorporation of the deictic ti?ił to the left of the intonational boundary, which seems to indicate that the deictic element is treated here as a phonological word.

If the deictic is in fact a phonological word, this would concord nicely with the role of its referent as sentential theme and discourse topic. The odd position of the IP-boundary could be analyzed as setting off a focalized theme from the remainder of the sentence, in the same way that a phrase-boundary may be used to offset an adjunct, and the deictic could be interpreted as a third-person pronominal (a role it takes on in other environments) rather than as the head of a DP. This would give us a syntactic bracketing and re-gloss of (35b) as in (36), where the NP bibščab ?i ti?ił su?suq'wa?s totyika 'Little Mink and his younger cousin Tetyika' is interpreted as an appositive, post-posed theme:

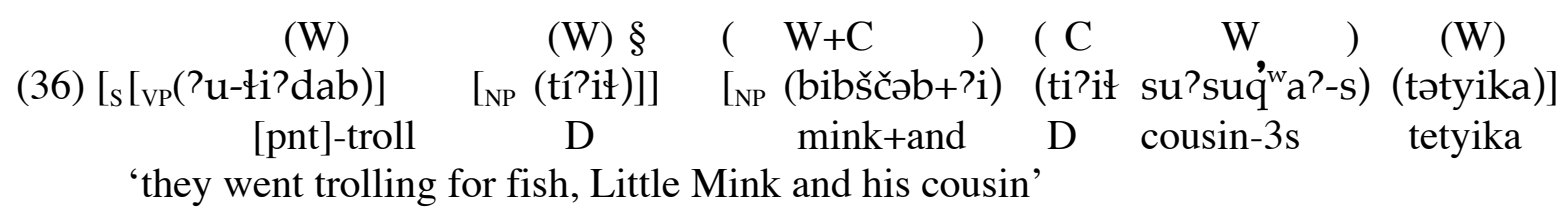

Note, however, that in the sentence in (35c) the focalized theme, sčətxəd 'Bear' remains in situ. This may indicate that these topic-setting structures do not involve syntactic right-dislocation, making the intonational phrasing of topic-setting structures more akin to that reported for Korean "focus" constructions by Selkirk (1996). In these constructions, an intonational boundary is inserted within a syntactic unit and demarcates an "internal focus constituent" - a sentence element singled out for special attention by the speaker which is therefore set off from the rest of the sentence by an I-phrase boundary. While Korean "envelopes" the marked constituent in its own intonational contour, Lushootseed may merely place an IP-boundary immediately before the marked element, simply bifurcating the sentence and conferring on the deictic an otherwise unattested status as a phonological word. ${ }^{5}$ Whether or not this affects the syntactic status of the deictic (i.e. whether or not it is interpretable as the head of a DP or as a pronominal followed by an appositive NP) will have to await future investigation.

\footnotetext{
${ }^{5}$ Note that the violation of the syntactic constituent structure by this marked I-phrase boundary is not a purely Lushootseed idiosyncrasy -English makes use of such constructions as well, as in "Brought to you by ... the Children's Television Workshop". Thanks to David Bennett for this example.
} 
Phenomena such as internal focus and emphatic lengthening show that in certain marked cases discourse-level properties of individual elements in a sentence can influence their status as prosodic words; however, under normal circumstances defining the units of phonological phrasing requires reference to what are fundamentally phonological features of lexical items. Such information is almost certainly a part of the lexicon. This means that in Lushootseed, in addition to information about lexical class, morphological composition, and segmental composition, entries for syntactically unbound elements must also contain information which identifies that element as either a phonological head (a word) or a non-head (a clitic). Variable words such as adverbs could then be treated as underspecified for this feature, allowing us to make use of the same constraints on phrase-formation developed in section 2.1 without recourse to any further machinery. This is shown in (37), which illustrates a subset of the output candidates for (32a) above. Here the input contains two underspecified elements (U) - the adverbs hik w'big' and ha?t 'good':

(37) Input: [UUCW]

\begin{tabular}{||lc||c:c:c|c||}
\hline & Candidates & NPC & SPO & $\begin{array}{c}\text { PARS } \\
\text { E }\end{array}$ & DI \\
\hline \hline a. & $(\mathrm{W})(\mathrm{W})(\mathrm{C} \mathrm{W})$ & & $* ! *$ & & \\
\hline b. & $(\mathrm{W})(\mathrm{C} \mathrm{C}+\mathrm{W})$ & & $* !$ & & $*$ \\
\hline c. & $(\mathrm{W} \mathrm{C})(\mathrm{C} \mathrm{W})$ & $* !$ & $*$ & & \\
\hline d. & $(\mathrm{W}+\mathrm{C})(\mathrm{C} \mathrm{W})$ & & $* !$ & & $*$ \\
\hline e. & $(\mathrm{C})(\mathrm{C})(\mathrm{C} \mathrm{W})$ & & & $* ! *$ & \\
\hline f. & & & & & \\
\hline
\end{tabular}

In (38), the same constraints predict the realization of $h i k^{w}$ in (32b) as a phonological word:

(38) Input: [UCCCWC]

\begin{tabular}{||lc||c:c:c|c||}
\hline & Candidates & NPC & SPO & PARS & DI \\
\hline \hline a. & $(\mathrm{W})(\mathrm{C} \mathrm{C} \mathrm{C} \mathrm{W})$ & & $* * * !$ & & \\
\hline b. & $(\mathrm{W})(\mathrm{C} \mathrm{C} \mathrm{C}+\mathrm{W})$ & & $* * !$ & & $*$ \\
\hline c. & $(\mathrm{W})(\mathrm{C} \mathrm{C}+\mathrm{C}+\mathrm{W})$ & & $* * !$ & & $* *$ \\
\hline d. & $(\mathrm{W} \mathrm{C})(\mathrm{C} \mathrm{C}+\mathrm{W})$ & $*$ & $* !$ & & $*$ \\
\hline e. & $(\mathrm{C})(\mathrm{C} \mathrm{C} \mathrm{C}+\mathrm{W})$ & & $*$ & $* !$ & $*$ \\
\hline f. $\quad$ 学 $(\mathrm{W}+\mathrm{C})(\mathrm{C} \mathrm{C}+\mathrm{W})$ & & $*$ & & $* *$ \\
\hline
\end{tabular}


As these examples show, the treatment of prosodically variable words such as $h i k^{w}$ and $h a ?$ can be dealt with in terms of a lack of inherent specification of their prosodic status, just as the behaviour of other elements in numerous examples throughout this paper can be dealt with in terms of their underlying specification in the lexicon as phonological clitics or words.

In the end, however, being or not being specified as a phonological word does not correlate in any useful way with the status of a given lexical item as an independent unit in the syntax. While it is true that there are correlations between the lexical class of a lexeme and its status as a phonological word (nouns and derived verbs are always phonological words, many types of function word are not), it is also true that elements such as pronouns, deictics, adverbial particles, and motion adverbs are autonomous syntactic units whose linear position is determined syntactically rather than morphonologically-and yet these elements are often realized as phonological affixes when this is necessary to meet needs of the phonology. Phonological word-, clitic-, or affix-hood, then, must be treated as a purely phonological feature whose value is either marked in the lexicon or left underspecified, to be determined according to the processes of phonological phrasing.

\section{Syntactic versus Phonological Word}

The data in the preceding sections show that phrasing is a phonological process governed by purely prosodic constraints on the patterning of clitics and words. Lushootseed phrases optimally consist of a single phonological word or clitic-word sequence and violations of this template are dealt with by processes of phonological incorporation or affix-formation, whereby clitics which appear in phrasal codas or adjacent to phonological heads in CC strings are treated phonologically as if they were morphological affixes, effectively hiding them from the prosodic processes of the language. These processes also appear to operate autonomously from syntactic structures and cut freely across most syntactic boundaries within the immediately governing IP, which itself sets the domain of phonological phrasing. The IP, in turn, is sensitive to some 
aspects of syntactic structure, as well as to such factors as intonational focus, breath groups, and rate of speech.

Most significantly, evidence from variable-category words shows quite clearly that in Lushootseed the syntactic word is not the equivalent of the phonological word and that the units manipulated by the syntax are not mapped one-to-one onto the units manipulated by the wordlevel phonology of the language-indeed, very often lexical items such as pronouns, deictics, prepositions, and adverbs are treated not only as unstressed elements within the immediate phonological phrase, but are actually treated as affixes, becoming phonologically part of a larger prosodic word. The fact that Lushootseed has a prosodically-driven process that converts syntactically free elements into phonological affixes may shed some light on the traditionally morphosyntactic cline from isolating to polysynthetic languages: Lushootseed, which is intermediate on the scale of polysynthesis, incorporates syntactically free elements into phrases which resemble but are not exactly phonological words, in that clitics within the $\mathrm{PhP}$ are distinguishable from incorporated elements and true affixes (or from affixes created from clitics in special prosodic environments). In languages which are more polysynthetic, it may be the case that the difference between clitic and affix becomes even less distinct, narrowing the gap between the phonological word and the phonological phrase, leading ultimately to the possibility that in a given language the extent to which phonological phrases resemble words (i.e. as phraseformation moves from grouping words $>$ cliticization $>$ affixation) is a measure of its degree of polysynthesis. Thus, polysynthesis can be treated as, rather than a morphosyntactic issue, an issue of phonology and of the extent to which the processes of phonological word formation override syntactic divisions in an utterance, making polysynthesis a measure of (or at least the diachronic product of) variations in prosodic organization and its relation to the syntactic and morphological structure of language. 


\section{References}

Barthmaier, P. (1998). Lushootseed vowels: A preliminary phonetic study. In Papers for the 33rd International Conference on Salish and Neighbouring Languages, 1 - 11. Seattle: University of Washington.

Bates, D., Hess, T. M., \& Hilbert, V. (1994). Lushootseed dictionary. Seattle: University of Washington Press.

Beck, D. J. (1996a). Subjecthood, agency, and topicality in Lushootseed. Toronto Working Papers in Linguistics 15(1). 1 - 29.

(1996b). Some notes on phonological phrasing in Lushootseed. Toronto Working Papers in Linguistics 15(2), $37-60$.

(1997). Rheme, Theme, and communicative structure in Lushootseed and Bella Coola. In Leo Wanner (Ed.), Recent trends in Meaning-Text Theory, 93 - 135. Amsterdam: Benjamins.

Bianco, V. (1995). Stress in Lushootseed-A preliminary analysis. In Papers for the 30th International Conference on Salish and Neighbouring Languages, 127 - 36. Victoria: University of Victoria.

Chen, M. (1987). The syntax of Xiamen tone sandhi. Phonology Yearbook 4, 109 - 49.

Cowper, E. A., \& Rice, K. D. (1987). Are phonosyntactic rules necessary? Phonology Yearbook 4, $185-194$.

Czaykowska-Higgins, E. (1997) The morphological and phonological constituent structure of words in Moses-Columbian Salish (Nxa?amxcín). In E. Czaykowska-Higgins \& M. D. Kinkade (Eds.), Salish languages and linguistics: Theoretical and descriptive perspectives, 153 - 96. Berlin: Mouton.

Evans, N. (1995.) Current issues in the phonology of Australian languages. In J. Goldsmith (Ed.), The Handbook of Phonological Theory, 723 - 61. Cambridge: Blackwell

Hess, T. M. (1976). Dictionary of Puget Salish. Seattle: University of Washington Press.

(1995). Lushootseed reader with introductory grammar: Volume I-Four stories from Edward Sam. University of Montana Occasional Papers in Linguistics 11. Missoula: University of Montana.

(to appear). Lushootseed reader with introductory grammar: Volume II. University of Montana Occasional Papers in Linguistics. Missoula: University of Montana.

Hess, T. M., \& Hilbert, V. (1976). Lushootseed: An introduction, Books 1 and 2. University of Washington: American Indian Studies.

Inkelas, S. \& Zec, D. (1990). Prosodically constrained syntax. In S. Inkelas \& D. Zec (Eds.), The phonology-syntax connection, (365 - 378). Chicago: CSLI. 
Jelinek, E. (1993). Languages without determiner quantification. Ms., University of Arizona.

Kinkade, M. D. (1983). Salishan evidence against the universality of 'noun' and 'verb'. Lingua $60,25-40$.

Matthewson, L. \& Davis, H. (1995). The structure of DP in Státimcets (Lillooet Salish). In Papers for the 30 th International Conference on Salish and Neighbouring Languages. Victoria, B.C.: University of Victoria.

McCarthy, J., \& Prince, A. (1993). Prosodic Morphology I: Constraint interaction and satisfaction. Ms, University of Massachusetts and Brandeis University.

Nespor, M., \& Vogel, I. (1986). Prosodic Phonology. Dordrecht: Foris.

Prince, A., \& Smolensky, P. (1993). Optimality theory. Ms., Rutgers University and the University of Colorado at Boulder.

Pu, M., \& Prideaux, G. D. (1994). Coding episode boundaries with marked structures: A crosslinguistic study. Canadian Journal of Linguistics 39, 283 - 296.

Rice, K. (1993). The structure of the Slave (Northern Athapaskan) verb. In S. Hargus \& E. Kaise (Eds.), Phonetics and phonology 4: Studies in lexical phonology, 145 - 71. San Diego: Academic Press.

Russell, K. (this volume). The "word" in two polysynthetic languages.

Selkirk, E. (1995a). Sentence prosody: Intonation, stress, and phrasing. In J. Goldsmith (Ed.), The Handbook of Phonological Theory, 550 - 69. Cambridge, MA: Blackwell.

(1996). Prosodic reflexes of focus. In Proceedings of the Workshop on Focus. Amherst: University of Massachusetts Graduate Linguistics Students Association.

Trask, R. L. (1993). A dictionary of grammatical terms in linguistics. London: Routledge.

van Eijk, J. P., \& Hess, T. M. (1986). Noun and verb in Salishan. Lingua 69, 319 - 331. 